\title{
Systematic Review \\ The Presence of Periodontitis in Patients with Von Willebrand Disease: A Systematic Review
}

\author{
Alexandru Mester ${ }^{1}{ }^{(}$, Leonardo Mancini ${ }^{2, *}$, Enrico Marchetti ${ }^{2}{ }^{\oplus}$, Mihaela Baciut $^{3}$, Simion Bran ${ }^{3}$, \\ Ondine Lucaciu ${ }^{1}$, Grigore Baciut ${ }^{3}$, Ciprian Tomuleasa ${ }^{4}{ }^{\circledR}$, Sergiu Pasca ${ }^{4}$, Andra Piciu ${ }^{5}{ }^{(}$, \\ Andrada Voina-Tonea ${ }^{6, *}$, Horia Opris ${ }^{3}\left[\right.$, Daiana Antoaneta Prodan ${ }^{3}$ and Florin Onisor ${ }^{3}(\mathbb{C}$
}

1 Department of Oral Health, University of Medicine and Pharmacy, Iuliu Hatieganu, 400012 Cluj-Napoca, Romania; mester.alexandru@umfcluj.ro (A.M.); patricia.lucaciu@umfcluj.ro (O.L.)

2 Department of Life, Health and Environmental Sciences, University of L'Aquila, 67100 L'Aquila, Italy; enrico.marchetti@univaq.it

3 Department of Maxillofacial Surgery and Implantology, University of Medicine and Pharmacy, Iuliu Hatieganu, 400012 Cluj-Napoca, Romania; mbaciut@umfcluj.ro (M.B.); dr_brans@umfcluj.ro (S.B.); gbaciut@umfcluj.ro (G.B.); horia.opris@umfcluj.ro (H.O.); daiana.prodan@umfcluj.ro (D.A.P.); florin.onisor@umfcluj.ro (F.O.)

4 Department of Hematology, University of Medicine and Pharmacy, Iuliu Hatieganu, 400012 Cluj-Napoca, Romania; ciprian.tomuleasa@umfcluj.ro (C.T.); pasca.sergiu@elearn.umfcluj.ro (S.P.)

5 Department of Medical Oncology, University of Medicine and Pharmacy, Iuliu Hatieganu, 400012 Cluj-Napoca, Romania; andra.piciu@umfcluj.ro

6 Department of Dental Materials, University of Medicine and Pharmacy, Iuliu Hatieganu, 400012 Cluj-Napoca, Romania

* Correspondence: leonardo.mancini@graduate.univaq.it (L.M.); andrada.tonea@umfcluj.ro (A.V.-T.)

Citation: Mester, A.; Mancini, L.; Marchetti, E.; Baciut, M.; Bran, S.; Lucaciu, O.; Baciut, G.; Tomuleasa, C.; Pasca, S.; Piciu, A.; et al. The Presence of Periodontitis in Patients with Von Willebrand Disease: A Systematic Review. Appl. Sci. 2021, 11, 6408. https://doi.org/10.3390/app11146408

Academic Editor: Ionut Luchian

Received: 4 June 2021

Accepted: 9 July 2021

Published: 12 July 2021

Publisher's Note: MDPI stays neutral with regard to jurisdictional claims in published maps and institutional affiliations.

Copyright: (c) 2021 by the authors. Licensee MDPI, Basel, Switzerland. This article is an open access article distributed under the terms and conditions of the Creative Commons Attribution (CC BY) license (https:// creativecommons.org/licenses/by/ $4.0 /)$.

\begin{abstract}
The aim of this systematic review and meta-analysis was to analyze the available evidence on the assessment of periodontal disease in patients with von Willebrand disease (VWD). An electronic search in three databases (PubMed, Web of Science, and Scopus) was conducted by three independent reviewers to identify cross-sectional, cohort, and clinical trial studies. Studies considered eligible for this review were evaluated according to the quality and risk assessment tool proposed by the CLARITY Group at McMaster University. In order to analyze the possible correlation of VWD patients and periodontitis and their susceptibility to bleeding during the periodontal screening phase, periodontal parameters evaluated were probing pocket depth (PPD), bleeding on probing (BOP), gingival bleeding index (GBI), and periodontal inflamed surface area (PISA). After a screening of 562 articles, three articles were selected for the qualitative analysis. Within the limitation of our review, VWD patients are not more susceptible to periodontitis as compared with non-VWD patients. Nevertheless, bleeding on probing and gingival index needs to be carefully taken into consideration during periodontal screening of VWD due to the possible presence of false positives.
\end{abstract}

Keywords: periodontal disease; periodontitis; gingivitis; von Willebrand disease

\section{Introduction}

Periodontal disease is included by the World Health Organization (WHO) in the category of most recurring pathologies related to oral health, next to dental cavities, microbial infections, tumors, and injuries. Up to $20 \%$ of the European population aged 35-44 suffer from advanced clinical forms of periodontitis, the percentage being significantly higher in the elderly population. In Europe, $40 \%$ of people between 65 and 70 years old are targeted by this condition [1]. In general, studies concluded that periodontal pathologies affect up to $50 \%$ of the entire globe population [2]. The various etiological components of the pathology represented by microbial load, personal defense mechanisms, existing degrees of inflammation, and background circumstances coexist and determine the complex definition of periodontal disease [3]. 
Von Willebrand disease (VWD) is known as the most common genetic hemorrhagic disorder $[4,5]$, determined by the anomaly in the quality or quantity of von Willebrand factor (VWF):

Type 1. A quantitative deficiency of VWF, the most common autosomal dominant form. Type 2. A qualitative alteration of VWF synthesis, which can result from various genetic abnormalities with autosomal dominant inheritance.

Type 3. A rare autosomal recessive disease in which homozygotes have no detectable von Willebrand factor activity.

VWF is an adhesion glycoprotein, with multiple roles in the process of coagulation. The most important role of this glycoprotein is to adhere to coagulation factor VIII, platelets and damaged subendothelium [5], as reported in Figure 1. Clinical signs of von Willebrand disease include nasal, conjunctival, or oral mucosal bleeding [4-6], persistent bleeding after minor trauma or dental extractions [7], excessive blood loss during menstrual periods [8], or bleeding of the gastrointestinal mucosa [9]. Among other systemic conditions that can coexist with periodontal disease, hemophilia expressed by VWD is known to affect the periodontal tissue [10]. Subsequently, the hemorrhagic risk is important not only in the manifestations of periodontal disease itself, but also during the periodontal treatment. Patients undergoing periodontal treatment measurements would benefit from specific therapeutic approaches, with the goal of diminishing the occurrence of prolonged bleeding times. Surgical and nonsurgical periodontal treatment must be performed in collaboration with the hematologist, in order to meet all the complex requirements of patients with hematological pathologies [10]. Procedures of bone and graft reconstruction must have constrained indications, even though modern technologies and equipment are nowadays available. Treatment measurements must be redirected to substitute procedures that are able to minimize the hemorrhagic risk [11].

\section{Bleeding stops with clot formation}

\section{With VWD no clot formation and bleeding}

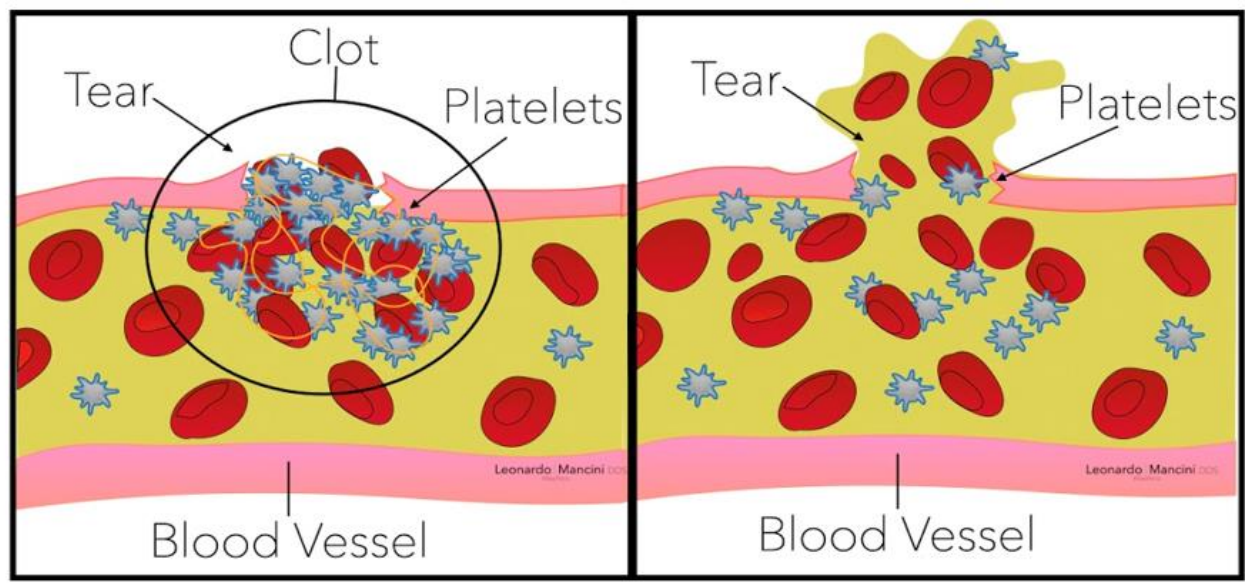

Figure 1. Differences in the clot formation of normal conditions and with VWD alteration.

The dental management of patients with VWD must focus on preventive measures in order to decrease the occurrence of periodontal pathologies. The avoidant brushing behavior of patients must also be taken into consideration, given their concerns not to self-cause gingival hemorrhages [12]. The lack of dental hygiene associated with the presence of sulcular microbiota make individuals who suffer from hemophilia disorders more vulnerable to periodontal pathologies, causing a long chain of complications, which must be managed by the dental care professionals in association with the hematologist [13]. Regular dental examinations, preventive measurements, and treatment approaches must represent a part of the therapeutic management plan of hemorrhagic patients [13]. 
Therefore, the aim of this systematic review and meta-analysis was to critically analyze the available evidence on the association of periodontal disease in patients with von Willebrand disease.

\section{Materials and Methods}

\subsection{Protocol Registration}

This systematic review was prepared according to the PRISMA guidelines [14] and the protocol details were registered in the PROSPERO database under the code CRD42021246930. The focused question of the present study was: "Does von Willebrand disease facilitate the onset and progression of periodontitis?"

\subsection{Eligibility Criteria}

2.2.1. Inclusion Criteria (PECO Framework)

The inclusion criteria included the following:

(a) Population, adult patients $>18$ years;

(b) Exposure, patients with VWD;

(c) Comparison, patients without VWD;

(d) Outcome, Primary periodontal parameters (probing pocket depth (PPD), bleeding on probing $(\mathrm{BOP})$, gingival bleeding index $(\mathrm{GBI})$, and periodontal inflamed surface area (PISA)).

\subsubsection{Exclusion Criteria}

The exclusion criteria included the following:

(a) Animal in vitro studies; not clinical trial, cross-sectional, or cohort studies; reviews; case reports; letters to the editor;

(b) Missing data regarding periodontal parameters (PPD, BOP, GBI, and PISA) and Von Willebrand parameters (von Willebrand factor (VWF) antigen and VWF activity);

(c) Predictive and prognostic studies;

(d) Insufficient data that could not be used for the meta-analysis;

(e) Studies published in other languages than English.

\subsection{Information Source and Search Process}

An electronic literature search on three databases (PubMed, Scopus, and Web of Science) was screened by three independent reviewers. A manual search was carried out on relevant journals such as the Journal of Clinical Periodontology, Journal of Periodontology, Journal of Periodontal Research and Journal of Periodontics and Restorative Dentistry. Relevant articles were examined in full-text and those who met the inclusion criteria were included after the reviewers confirmed in an open discussion. If disagreements were present, a fourth reviewer intervened with an additional investigation. The level of agreement between reviewers was established using Cohen's kappa. The electronic search on databases was performed until April 2021 to identify relevant articles, using the following search strategy: ("Periodontal disease" OR "periodontitis" OR "periodontal health" OR "periodontal lesion" OR "periodontal bleeding" OR "gingivitis" OR "gingival health" OR "gingival lesion" OR "gingival bleeding") AND ("Von Willebrand disease" OR "Von Willebrand disease type 1" OR "Von Willebrand disease type 2" OR "Von Willebrand disease type 3").

\subsection{Data Extraction}

The same reviewers extracted the following data from the included studies and possible errors were excluded by the third reviewer: first author, year of study, country, reference; study type; participants; characteristics of participants; hematology analysis; periodontal disease parameters; results; conclusions. In the case of an article in which the results were published more than one time, only the article with the longest follow-up data was taken into account. If necessary, authors were contacted via email to provide missing data. 


\subsection{Risk of Bias Assessment}

All the included studies were evaluated according to the quality and risk assessment tool proposed by the CLARITY Group at McMaster University which is recognized as the specific assessment for case-control studies [15,16]. A scoring system was used to obtain an objective quality. Each study was considered at low, moderate, or high risk of bias according to 5 questions. From these 5 questions, the assessment was settled as low risk of bias for 5 positive answers, moderate for 4 , and high risk of bias less than 4 . The questions were as follows:

(a) Can we be confident in the assessment of exposure?

(b) Can we be confident that cases had developed the outcome of interest and controls had not?

(c) Were the cases (those who were exposed and developed the outcome of interest) properly selected?

(d) Were the controls (those who were exposed and did not develop the outcome of interest) properly selected?

(e) Were cases and controls matched according to important prognostic variables or was statistical did adjustment carry out for those variables?

\section{Results}

\subsection{Study Selection}

The initial electronic search in selected databases delivered a total of 762 articles, of which, 200 articles were duplicates. After excluding the duplicates, 562 articles were reviewed through title and abstract. Then, 554 articles were excluded because they did not meet the required inclusion criteria. Therefore, 8 articles resulted as eligible; five articles were excluded because they did not mention what parameters they used for quantification of periodontitis, or they mentioned few periodontal parameters. In the end, three articles were included for qualitative synthesis and two articles were included for the meta-analysis. Figure 2 indicates the flowchart of this review.

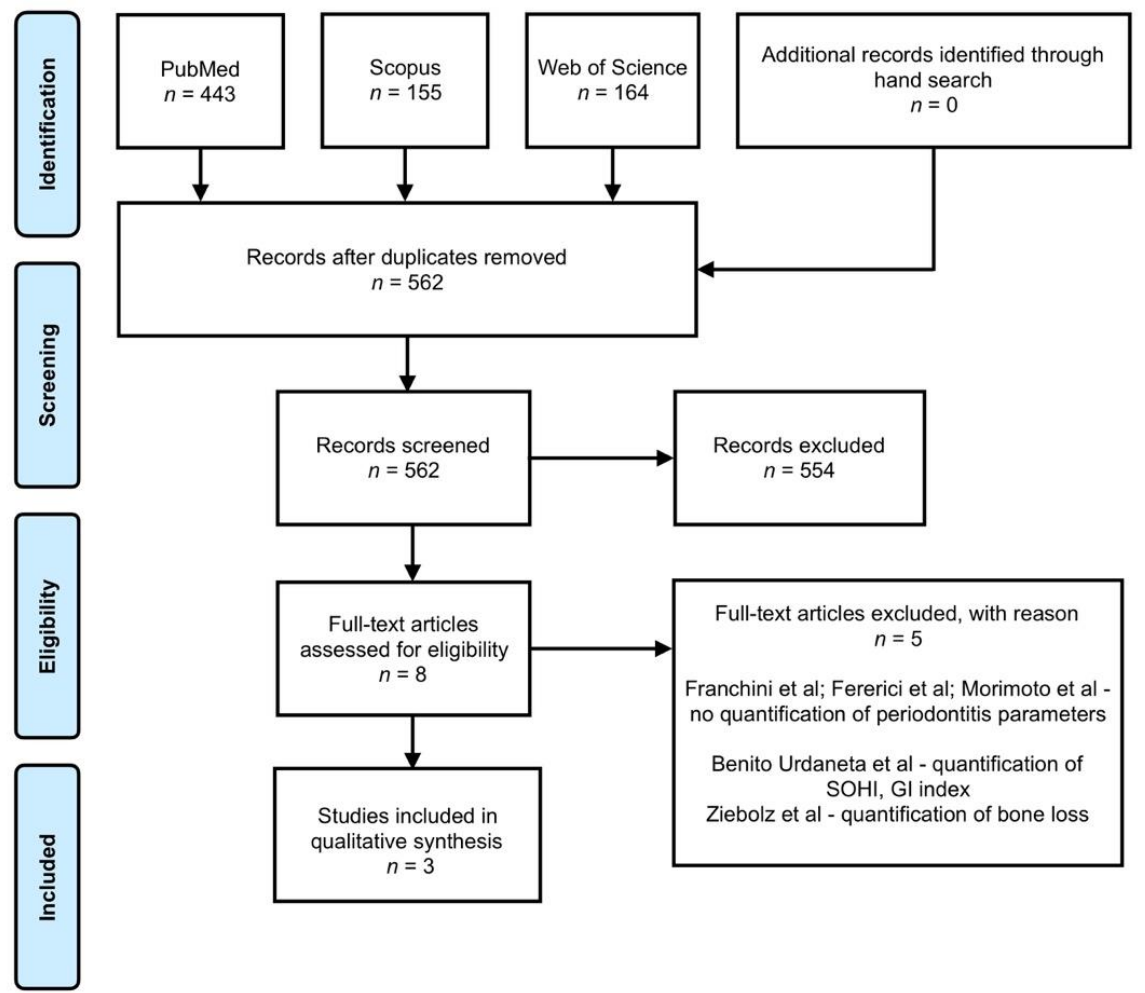

Figure 2. Prisma flowchart. 


\subsection{Study Characteristics}

The included articles were developed in Germany. Articles were published in English language between 2014 and 2016. Regarding the study design, two articles were prospective case control, and one article was case control. The total sample size in the control groups of the previously mentioned studies was 104 patients; in the VWD Type 1 group there was 100 patients and in the VWD Type 2 and 3 groups there was 24 patients. The mean age varied in the included patients and was between 42 and 47 years for the control groups and between 42 and 46 years for the VWD groups. Gender distribution of the participants was mentioned in the included studies.

Periodontal disease was clearly defined in all studies and the following periodontal parameters were assessed: BOP, GBI, PPD, PCR, and PISA. Regarding the presence of periodontal pathology, in the control group sample, there were 37 patients with gingivitis and 67 patients with periodontitis. In the VWD group sample, there were 37 patients with gingivitis and 87 patients with periodontitis. Hematological examinations for VWD disease were assessed in all studies using the following parameters: VWF antigen, VWF activity, ristocetin cofactor, and factor VIII.

\subsection{Risk of Bias for Individual Studies}

Risk of bias was carried out with the RoB tool modified for case control studies according to the Macmaster protocol by two independent reviewers (Cohen's $\mathrm{K}=1$ ). It revealed two studies at low risk of bias and one study at moderate risk of bias, as reported in Figure 3.

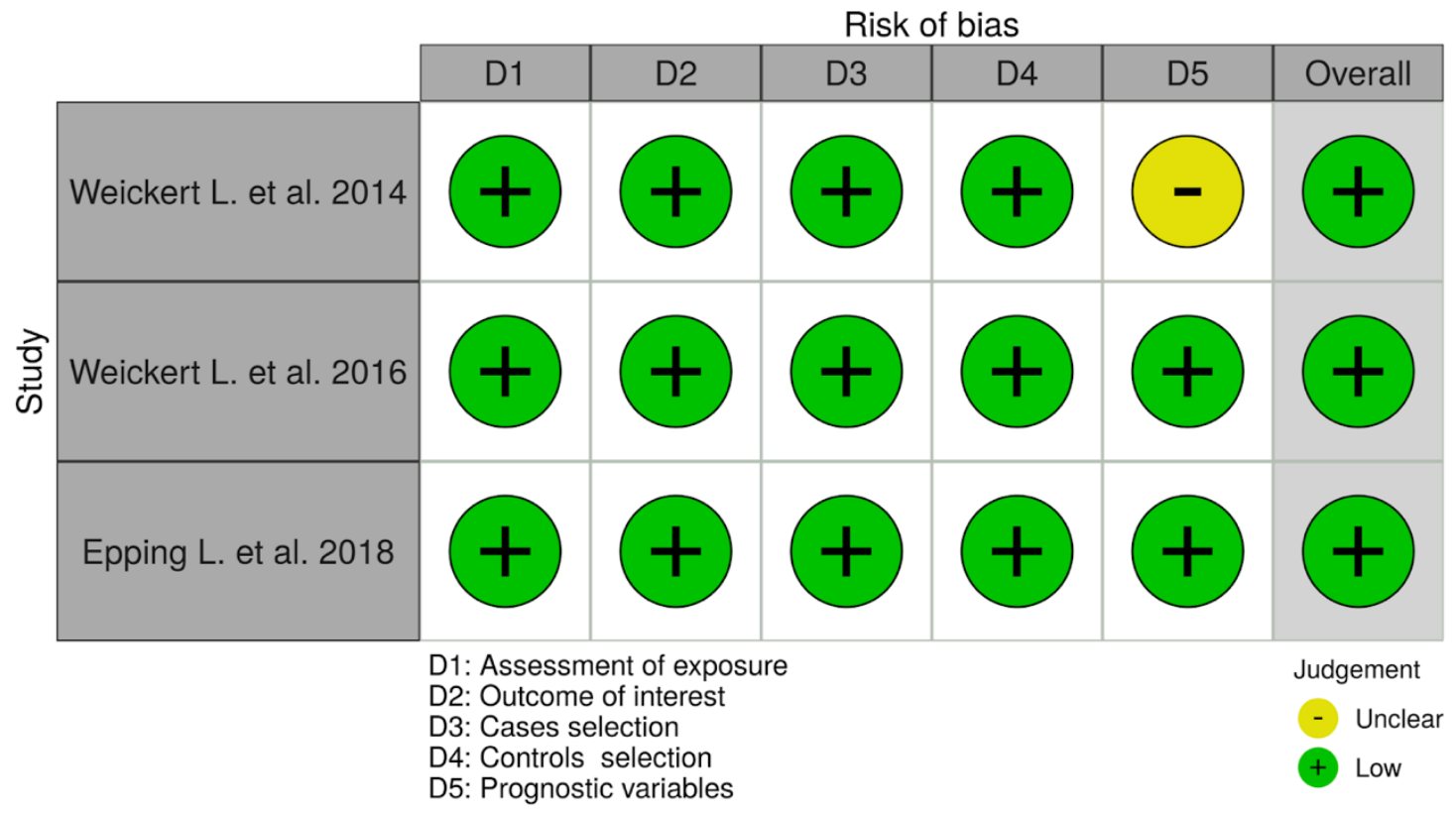

Figure 3. Risk of bias for each study according to the McMaster tool.

\subsection{Qualitative Synthesis}

A moderate agreement between the reviewers (Cohen's $\mathrm{K}=0.45$ ) resulted in the inclusion of three studies. In the study of Weickert et al. 2014 [17], BOP showed no major difference between the VWD group $(14.5 \pm 10.1 \%)$ and control $(12.3 \pm 5.3 \%)$. Weickert and coworkers 2017 [18], obtained BoP values of $17.0 \pm 7.2 \%$ for the VWD group and $17.2 \pm 7.6 \%$ for the control group. Epping et al. [19] obtained BoP values of $14.5 \pm 10.1 \%$ for the VWD group and $12.3 \pm 5.3 \%$ for the control group. The VWD factor was higher than the control confirming the inclusion of the right population, and thus according to the extracted data collected in Table 1, patients with VWD disease are not more susceptible to periodontitis as compared with periodontal patients. 
Table 1. Characteristics of the included studies.

\begin{tabular}{|c|c|c|c|c|c|c|c|}
\hline $\begin{array}{l}\text { Author. Year. Country. } \\
\text { Reference }\end{array}$ & Study Type & Participants & $\begin{array}{l}\text { Characteristics of } \\
\text { Participants }\end{array}$ & Hematology Analysis & $\begin{array}{l}\text { Periodontal Disease } \\
\text { Parameters }\end{array}$ & Results & Conclusions \\
\hline 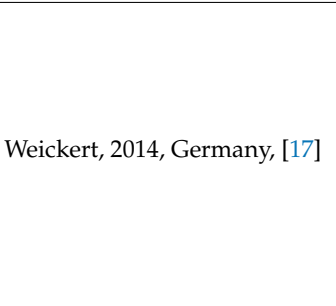 & $\begin{array}{l}\text { Prospective case } \\
\text { control }\end{array}$ & $\begin{array}{c}\text { Control }(n=40) \\
\text { VWD Type } 1(n=50)\end{array}$ & $\begin{array}{c}\text { Control: } \\
\text { Female }(n=34) \\
\text { Male }(n=6) \\
\text { Gingivitis }(n=13) \\
\text { Periodontitis }(n=27) \\
\text { VWD: } \\
\text { Female }(n=43) \\
\text { Male }(n=7) \\
\text { Gingivitis }(n=13) \\
\text { Periodontitis }(n=37) \\
\text { Control: }\end{array}$ & $\begin{array}{l}\text { VWF antigen } \\
\text { Ristocetin cofactor } \\
\text { Factor VIII }\end{array}$ & $\begin{array}{l}\text { BOP } \\
\text { GBI } \\
\text { PPD } \\
\text { PCR }\end{array}$ & $\begin{array}{c}\text { BOP (VWD } 14.5 \pm 10.1 \% \text {, control } 12.3 \pm 5.3 \% \text { ) } \\
\text { GBI (VWD 10.5 } \pm 9.9 \% \text {, control } 8.8 \pm 4.8 \% \text { ) } \\
\text { PPD (VWD 1.8 } \pm 0.9 \mathrm{~mm} \text {, control } 1.9 \pm 0.5 \mathrm{~mm} \text { ) } \\
\text { PCR (VWD 53. } \pm 24.1 \% \text {, control } 49.5 \pm 15.9 \% \text { ) } \\
\text { VWF antigen (VWD } 62.6 \pm 15.4 \% \text {, control } \\
111.8 \pm 27.4 \% \text { ) } \\
\text { Ristocetin cofactor (VWD 47.2 } \pm 10.0 \% \text {, control: } \\
91.6 \pm 26.0 \%) \\
\text { Factor VIII (VWD } 84.6 \pm 17.7 \% \text {, control } \\
108.6 \pm 21.1 \% \text { ) }\end{array}$ & $\begin{array}{l}\text { VWD is not associated } \\
\text { with pronounced } \\
\text { inflammatory response to } \\
\text { oral biofilm (in terms of } \\
\text { GBI, BOP). }\end{array}$ \\
\hline Weickert, 2016, Germany, [18] & Case Control & $\begin{array}{c}\text { Control }(n=40) \\
\text { VWD Type } 1(n=50)\end{array}$ & $\begin{array}{c}\text { Female }(n=34) \\
\text { Male }(n=6) \\
\text { Gingivitis }(n=13) \\
\text { Periodontitis }(n=27) \\
\text { VWD: } \\
\text { Female }(n=43) \\
\text { Male }(n=7) \\
\text { Gingivitis }(n=13) \\
\text { Periodontitis }(n=37)\end{array}$ & $\begin{array}{l}\text { VWF antigen } \\
\text { Ristocetin cofactor } \\
\text { Factor VIII }\end{array}$ & $\begin{array}{l}\text { BOP } \\
\text { GBI }\end{array}$ & $\begin{array}{c}\text { BOP (VWD } 17.0 \pm 7.2 \% \text {, control } 17.2 \pm 7.6 \% \text { ) } \\
\text { GBI (VWD 10.0 } \pm 5.0 \% \text {, control 12.2 } \pm 5.5 \% \text { ) } \\
\text { VWF antigen (VWD } 62.6 \pm 15.4 \% \text {, control } \\
111.8 \pm 27.4 \%) \\
\text { Ristocetin cofactor (VWD } 47.2 \pm 10.0 \% \text {, control } \\
91.6 \pm 26.0 \%) \\
\text { Factor VIII (VWD } 84.6 \pm 17.7 \% \text {, control } \\
108.6 \pm 21.1 \%)\end{array}$ & $\begin{array}{l}\text { Gingival bleeding in VWD } \\
\text { type } 1 \text { patients might be } \\
\text { determined by gingival } \\
\text { inflammation. }\end{array}$ \\
\hline Epping, 2018, Germany [19] & $\begin{array}{l}\text { Prospective case } \\
\text { control }\end{array}$ & $\begin{array}{c}\text { Control }(n=24) \\
\text { VWD Type 2,3 } \\
\quad(n=24)\end{array}$ & $\begin{array}{c}\text { Control: } \\
\text { Female }(n=17) \\
\text { Male }(n=7) \\
\text { Gingivitis }(n=11) \\
\text { Periodontitis }(n=13) \\
\text { VWD: } \\
\text { Female }(n=17) \\
\text { Male }(n=7) \\
\text { Gingivitis }(n=11) \\
\text { Periodontitis }(n=13)\end{array}$ & $\begin{array}{l}\text { VWF antigen } \\
\text { VWF activity } \\
\text { Factor VIII }\end{array}$ & $\begin{array}{l}\text { BOP } \\
\text { GBI } \\
\text { PPD } \\
\text { PCR } \\
\text { PISA }\end{array}$ & 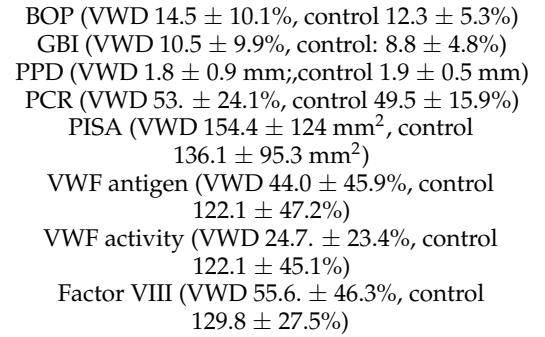 & $\begin{array}{l}\text { VWD is not associated } \\
\text { with a higher } \\
\text { inflammatory response to } \\
\text { the oral biofilm. } \\
\text { In terms of BOP and GBI, } \\
\text { this study failed to detect } \\
\text { increased gingival } \\
\text { bleeding in VWD patients. }\end{array}$ \\
\hline
\end{tabular}

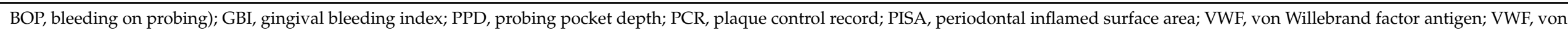

Willebrand factor activity; ristocetin cofactor; factor VIII. 


\section{Discussion}

The correlation between periodontal health and bleeding disorders has been studied over the years. Studies have proven that hemophilic patients exhibit higher index values of gingival bleeding, plaque accumulation, and increased numbers of teeth affected by carious processes/extractions [20]. Nevertheless, no direct interrelationship has been detected between VWD and periodontal inflammation, as a reaction to the microorganism aggregation [17-19]. Another important aspect that should be considered is circulating blood cells profiles. Botelho and collaborators published a meta-analysis in which they analyzed the hemogram, leukogram, and thrombogram between periodontitis and control patients [21]. They concluded that periodontitis is associated with hematologic changes (high white blood cells, neutrophils, erythrocyte, and low mean platelet volume). Blood cell profiles may be a useful tool for the hematologist to decide in which dental settings a patient should be treated.

Periodontal treatments in patients with VWD must be performed under specific precautions. The evolution point of the periodontal pathology must be taken into consideration, as well the probing measurements and the oral health status of the patients. Topical substances, such as tranexamic acid, used in the management of bleeding while performing simple supragingival scaling procedures, are indicated in subjects with simple forms of VWD [22]. More evolved expressions of the disease require collaboration with the hematology department in order to initiate a substitute therapy [22]. Maneuvers that imply periodontal nonsurgical or surgical approaches require a minimum $50-75 \%$ value of factor VIII before the procedure [22]. Periodontal measures are crucial for maintaining the oral health of patients with VWD and must be initiated as soon as the periodontal status requires. Scaling procedures must be performed at different meetings, in order to prevent important hemorrhages. Inflammation and infection control must be applied, with the help of antibiotics and chlorhexidine gluconate, depending on the type of periodontal pathology [22,23]. Oral hygiene education and prophylactic measures are as important as therapeutic procedures for patients with VWD, as they all concur in fighting the most important complication, i.e., excessive bleeding [24].

The professional relationship and collaboration between a dental practitioner and hematologist are very important, given the great risk during dental maneuvers [24,25]. Treatment protocol must be carefully guided by the hematologist, in order to perform safe therapeutic procedures $[24,25]$. Lack of communication in this process can lead to different complications related to delayed and excessive bleeding [24]. Speaking, swallowing, and breathing impediments have also been reported as undesired episodes among hemophilic patients, undergoing dental procedures [25].

According to our results, the possible susceptibility of patients with VWD to the onset and exacerbation of periodontitis is not relevant as compared with non-VWD periodontal patients. In the literature, there are few works about periodontitis and VWD and this is a limitation of our study; moreover, the test population was only represented by VWD type 1 patients; however, Epping and collaborators included patients with VWD type 2 and 3 [19]. As reported from the literature, the differences are underlined by the concentration of VWF antigen. Nevertheless, VWD patients affected by gingivitis/periodontitis should be treated as periodontally compromised; the surgical and nonsurgical periodontal therapy must be applied under control in order to reduce bleeding and hemorrhages.

\section{Conclusions}

Within the limitation of our review and the low number of included studies, VWD patients are not more susceptible to periodontitis as compared with non-VWD patients. Nevertheless, bleeding on probing and gingival index need to be carefully taken into consideration during periodontal screening of VWD due to the possible presence of false positives. More prospective studies with larger cohorts and longer periods of follow-up are needed. 
Author Contributions: Conceptualization, A.M., L.M., A.P., and A.V.-T.; methodology, A.M., L.M., A.P., and A.V.-T.; software, L.M.; validation, E.M., M.B., S.B., G.B., C.T., S.P., H.O., and D.A.P.; investigation, A.M., L.M., A.P., and A.V.-T.; writing-original draft, A.M., L.M., O.L., and A.V.-T.; writing-review and editing, A.M., L.M., and F.O.; supervision, F.O. All authors have read and agreed to the published version of the manuscript.

Funding: This study received funding by an international grant awarded by the Novo Nordisk Haemophilia Foundation 2020-2021 (grant director, Ciprian Tomuleasa).

Institutional Review Board Statement: Not applicable.

Informed Consent Statement: Not applicable.

Data Availability Statement: The authors confirm that the data supporting the findings of this study are available within the article.

Conflicts of Interest: The authors declare no conflict of interest.

\section{References}

1. WHO Data and Statistics on Oral Health. Available online: https://www.euro.who.int/en/health-topics/disease-prevention/ oral-health/data-and-statistics (accessed on 1 April 2021).

2. Nazir, M.A. Prevalence of periodontal disease, its association with systemic diseases and prevention. Int. J. Health Sci. 2017, $11,72-80$.

3. Lang, N.P.; Bartold, P.M. Periodontal health. J. Periodontol. 2018, 89 (Suppl. S1), S9-S16. [CrossRef] [PubMed]

4. Fogarty, H.; Doherty, D.; O'Donnell, J.S. New developments in von Willebrand disease. Br. J. Haematol. 2020, 191, 329-339. [CrossRef]

5. Kalot, M.A.; Al-Khatib, M.; Connell, N.T.; Flood, V.; Brignardello-Petersen, R.; James, P.; Mustafa, R.A. An international survey to inform priorities for new guidelines on von Willebrand disease. Haemophilia 2020, 26, 106-116. [CrossRef] [PubMed]

6. Metjian, A.D.; Wang, C.; Sood, S.L.; Cuker, A.; Peterson, S.M.; Soucie, J.M.; Konkle, B.A. Bleeding symptoms and laboratory correlation in patients with severe von Willebrand disease. Haemophilia 2009, 15, 918-925. [CrossRef]

7. Baghaie, H.; Forrest, B.; Shukla, K.; Liu, T. Dental extraction in a patient with undiagnosed Von Willebrand's Disease: A case report. Aust. Dent. J. 2021, 66, 105-111. [CrossRef] [PubMed]

8. Kouides, P.A.; Phatak, P.D.; Burkart, P.; Braggins, C.; Cox, C.; Bernstein, Z.; Belling, L.; Holmberg, P.; MacLaughlin, W.; Howard, F. Gynaecological and obstetrical morbidity in women with type I von Willebrand disease: Results of a patient survey. Haemophilia 2000, 6, 643-648. [CrossRef] [PubMed]

9. Makris, M. Gastrointestinal bleeding in von Willebrand disease. Thromb. Res. 2006, 118, S13-S17. [CrossRef]

10. Parvaie, P.; Shaygan Majd, H.; Ziaee, M.; Sharifzadeh, G.; Osmani, F. Evaluation of gum health status in hemophilia patients in Birjand (a case-control study). Am. J. Blood Res. 2020, 10, 54-59.

11. Ibsen Olga, P.J. Oral Pathology for the Dental Hygienis, 6th ed.; Saunders Elsevier: St. Louis, MO, USA, $2014 ;$ ISBN 9781455748266.

12. Anderson, J.A.M.; Brewer, A.; Creagh, D.; Hook, S.; Mainwaring, J.; McKernan, A.; Yee, T.T.; Yeung, C.A. Guidance on the dental management of patients with haemophilia and congenital bleeding disorders. Br. Dent. J. 2013, 215, 497-504. [CrossRef]

13. Shastry, S.P.; Kaul, R.; Baroudi, K.; Umar, D. Hemophilia A: Dental considerations and management. J. Int. Soc. Prev. Community Dent. 2014, 4, S147-S152.

14. Moher, D.; Shamseer, L.; Clarke, M.; Ghersi, D.; Liberati, A.; Petticrew, M.; Shekelle, P.; Stewart, L.A. Preferred reporting items for systematic review and meta-analysis protocols (PRISMA-P) 2015 statement. Syst. Rev. 2015, 4, 1. [CrossRef]

15. Benford, D.; Halldorsson, T.; Jeger, M.J.; Knutsen, H.K.; More, S.; Naegeli, H.; Noteborn, H.; Ockleford, C.; Ricci, A.; Rychen, G.; et al. The principles and methods behind EFSA's Guidance on Uncertainty Analysis in Scientific Assessment. EFSA J. Eur. Food Saf. Auth. 2018, 16, e05122.

16. von Hippel, P.T. The heterogeneity statistic I(2) can be biased in small meta-analyses. BMC Med. Res. Methodol. 2015, 15, 35. [CrossRef]

17. Weickert, L.; Miesbach, W.; Alesci, S.R.; Eickholz, P.; Nickles, K. Is gingival bleeding a symptom of patients with type 1 von Willebrand disease? A case-control study. J. Clin. Periodontol. 2014, 41, 766-771. [CrossRef]

18. Weickert, L.; Krekeler, S.; Nickles, K.; Eickholz, P.; Seifried, E.; Miesbach, W. Gingival bleeding and mild type 1 von Willebrand disease. Blood Coagul. Fibrinolysis Int. J. Haemost. Thromb. 2017, 28, 19-23. [CrossRef] [PubMed]

19. Epping, L.; Miesbach, W.; Nickles, K.; Eickholz, P. Is gingival bleeding a symptom of type 2 and 3 von Willebrand disease? PLoS ONE 2018, 13, e0191291. [CrossRef] [PubMed]

20. Azhar, S.; Yazdanie, N.; Muhammad, N. Periodontal status and IOTN interventions among young hemophiliacs. Haemophilia 2006, 12, 401-404. [CrossRef]

21. Botelho, J.; Machado, V.; Hussain, S.B.; Zehra, S.A.; Proença, L.; Orlandi, M.; Mendes, J.J.; D’Aiuto, F. Periodontitis and circulating blood cell profiles: A systematic review and meta-analysis. Exp. Hematol. 2021, 93, 1-13. [CrossRef] 
22. Abed, H.; Ainousa, A. Dental management of patients with inherited bleeding disorders: A multidisciplinary approach. Gen. Dent. 2017, 65, 56-60.

23. Correa, M.E.; Paulo, S. Guidelines for Dental Treatment of Patients with Inherited Bleeding Disorders; World Federation of Hemophilia: Montreal, QC, Canada, 2006.

24. Vinckier, F.; Vermylen, J. Dental extractions in hemophilia: Reflections on 10 years' experience. Oral Surg. Oral Med. Oral Pathol. 1985, 59, 6-9. [CrossRef]

25. Srivastava, A.; Brewer, A.K.; Mauser-Bunschoten, E.P.; Key, N.S.; Kitchen, S.; Llinas, A.; Ludlam, C.A.; Mahlangu, J.N.; Mulder, K.; Poon, M.C.; et al. Guidelines for the management of hemophilia. Haemophilia 2013, 19, e1-e47. [CrossRef] [PubMed] 